\title{
ARTICLES
}

\section{Likes, Comments, Views}

\section{A Content Analysis of Academic Library Instagram Posts}

Jylisa Doney, Olivia Wikle, and Jessica Martinez

\section{ABSTRACT}

This article presents a content analysis of academic library Instagram accounts at eleven land-grant universities. Previous research has examined personal, corporate, and university use of Instagram, but fewer studies have used this methodology to examine how academic libraries share content on this platform and the engagement generated by different categories of posts. Findings indicate that showcasing posts (highlighting library or campus resources) accounted for more than 50 percent of posts shared, while a much smaller percentage of posts reflected humanizing content (emphasizing warmth or humor) or crowdsourcing content (encouraging user feedback). Crowdsourcing posts generated the most likes on average, followed closely by orienting posts (situating the library within the campus community), while a larger proportion of crowdsourcing posts, compared to other post categories, included comments. The results of this study indicate that libraries should seek to create Instagram posts that include various types of content while also ensuring that the content shared reflects their unique campus contexts. By sharing a framework for analyzing library Instagram content, this article will provide libraries with the tools they need to more effectively identify the types of content their users respond to and enjoy as well as make their social media marketing on Instagram more impactful.

\section{INTRODUCTION}

Library use of social media has steadily increased over time; in 2013, 86 percent of libraries reported using social media to connect with their patron communities. ${ }^{1}$ The ways in which libraries use social media tend to vary, but common themes include marketing services, content, and spaces to patrons, as well as creating a sense of community. ${ }^{2}$ Even with this wealth of research, fewer studies have examined how libraries use Instagram, and those that do often utilize a formal or informal case study methodology. ${ }^{3}$ This research seeks to fill that gap by examining the types of content shared most frequently by a subset of academic library Instagram accounts. Although this research focused on academic libraries, its methods and findings could be leveraged by educational institutions and non-profits in their own investigations of Instagram usage and impact.

\section{LITERATURE REVIEW}

Since its inception in 2010, Instagram's number of account holders has been steadily increasing. By 2019, more than one billion user accounts were active each month, making it the third most popular social media network in the world, and the Pew Research Center has reported that Instagram is the second most used social media platform among people ages 18-29 in the United States, after Facebook. ${ }^{4}$ Instagram has estimated that 90 percent of user accounts follow at least one business account. ${ }^{5}$ Previous research has also shown that individuals who use Instagram to follow specific brands have the highest rates of engagement with, and commitment to, those

Jylisa Doney (jylisadoney@uidaho.edu) is Social Sciences Librarian, University of Idaho. Olivia Wikle (omwikle@uidaho.edu) is Digital Initiatives Librarian, University of Idaho. Jessica Martinez (jessicamartinez@uidaho.edu) is Science Librarian, University of Idaho. (C) 2020. 
brands when compared to users of other social media platforms. ${ }^{6}$ Though businesses are fundamentally different in the products or services they are trying to market, academic libraries share a desire to provide information to, and engage with, their followers.

As such, in the past decade, libraries have begun to adopt Instagram as a way to market their libraries and interact with patrons. ${ }^{7}$ However, methods and parameters for libraries' use of Instagram vary across types of libraries and even within specific library types. ${ }^{8}$ Research has demonstrated that academic libraries' use of social media, including Instagram, is often for the purpose of increasing the sense of community among librarians and patrons by marketing the library's services and encouraging student feedback and interaction. ${ }^{9}$ Similarly, Harrison et al. discovered that academic library social media posts reflected three main themes: "community connections, inviting environment, and provision of content." ${ }^{10}$ Chatten and Roughley have also reported that libraries' use of social media ranges from providing customer service to promoting the library and building a community of users. ${ }^{11}$ Indeed, when comparing modern social networking systems, such as Instagram, to older platforms, such as Myspace, Fernandez posited that today's popular social media sites encourage networking and are especially suited to creating community. ${ }^{12}$ Ideally, community engagement in the virtual social media environment would encourage more patrons to enter the library and thus engage in more face-to-face encounters. ${ }^{13}$

Libraries' methods for measuring the success of their social media engagement are as varied as the ways in which they use social media. Assessment of libraries' social media efficacy is tricky, and highly variable from institution to institution. Hastings has cautioned that librarians should recognize that patrons both actively and passively interact with social media content. ${ }^{14}$ For this reason, while a large number of comments or likes may be identified as positive markers for active engagement, passive forms of engagement, such as the number of times a post appeared in users' Instagram feeds, may also be relevant. ${ }^{15}$ Therefore, when librarians measure the success of an Instagram post by examining only the number of likes and comments, they should be aware that they are measuring a very specific type of engagement: one which, on its own, may not determine a post's full reach or effectiveness. Other ways to measure engagement include monitoring how the number of people subscribed to an account changes over time, evaluating reach and impressions ${ }^{16}$ or analyzing the content of comments (a type of qualitative measure that may indicate the type of community developing around the library's social media).

Despite, or perhaps because of, the general excitement surrounding the possibilities that libraries' engagement with social media can produce, very little has been written about how different types of libraries (such as academic libraries, law libraries, public libraries, etc.), or libraries in general, use these platforms. ${ }^{17}$ Additionally, many librarians may lack expertise in marketing, including those who are managing social media accounts. ${ }^{18}$ As social media culture continues to evolve, librarians should move toward a more targeted and pragmatic approach to their Instagram practices. This refinement in social media practices may enable libraries to develop more structure, so that they may create and share the type of content that would achieve their desired result at a given time. However, in order to develop this kind of measured approach, it is necessary for researchers to first analyze libraries' current Instagram practices to determine how posts are being used and the outcomes they generate.

One effective method of analyzing Instagram content centers on coding and classifying images. While many such schemas have been developed for analyzing images posted by Instagram users and businesses, transferring these schemas to academic contexts has been difficult. ${ }^{19}$ To address 
this gap, Stuart et al. adapted a schema that had been used to examine how "news media [and] non-profits," as well as businesses, used Instagram. ${ }^{20}$ This new schema allowed Stuart et al. to classify Instagram posts produced by academic institutions in the UK and measure the effect of these universities' attempts to engage with students via Instagram. ${ }^{21}$ Stuart et al.'s schema, which classified Instagram images into six categories (orienting, humanizing, interacting, placemaking, showcasing, and crowdsourcing), was the basis for the present study. ${ }^{22}$

\section{METHODS}

\section{Research Questions}

The impetus for this study was to learn more about how academic libraries use Instagram to connect with their campus communities and promote their services and events. The authors of the present study adapted the research questions posed by Stuart et al. to reflect academic library contexts: ${ }^{23}$

- RQ1: Which type of post category is used most frequently by libraries on Instagram?

- RQ2: Is the number of likes or the existence of comments related to the post category?

\section{Identifying a Sample Population}

This study investigated a small subset of academic institutions: the University of Idaho's sixteen peer institutions. These peers have similar "student profiles, enrollment characteristics, research expenditures, [or] academic disciplines and degrees"; each is designated as a land-grant institution; and the University of Idaho considers three to be "aspirational peers." ${ }^{24}$ After selecting this population, the authors investigated the library websites of each of the sixteen peer institutions to determine whether or not they had a library-specific Instagram account. When a link was not available on the library websites, the authors conducted a search within Instagram as well as a general Google search in an attempt to identify these Instagram accounts. Of the University of Idaho's sixteen peer institutions, eleven had active, library-specific Instagram accounts.

\section{Data Collection}

The authors undertook manual data collection between November and December 2018 for these eleven library Instagram accounts. Initial information about each Instagram account was gathered prior to the study on October 23, 2018: the date of the first post, the total number of posts shared by the account, the total number of followers, and the total number of accounts followed. For each account, the authors identified posts shared from January 1, 2018, to June 30, 2018. The "print to PDF" function available in the Chrome browser was used to preserve a record of the content, in case the accounts were later discontinued while research was underway. If a post included more than one image, only the first image was captured in the PDF and analyzed. To organize the 377 Instagram posts shared within this timeframe, the authors assigned each institution a unique, fivedigit identifier; file names included this identifier as well as the date of the post (e.g., 00004_IGpost_20180423). This file naming convention ensured that posts were separated based on institution and that future studies could use the same file naming convention, even if the sample size increased significantly. The authors added the file names of all 377 Instagram posts to a shared Google Sheet, and for each post they reported the kind of post (photo or video), the number of likes, and whether comments existed. 


\section{Research Data Analysis}

Content Analysis

This project adapted the coding schema Stuart et al. employed to investigate the ways in which UK universities used Instagram. ${ }^{25}$ Expanding on research by McNely, Stuart et al. employed six Instagram post categories: orienting, humanizing, interacting, placemaking, showcasing, and crowdsourcing. ${ }^{26}$ For the purposes of the present study, the authors used the same category names when coding library Instagram posts. However, they updated and adapted the descriptions of each category over the course of two rounds of coding to better reflect academic library contexts (see table 1). Within this coding schema, the authors elected to apply only a single category name (i.e., a code) to each library Instagram post.

\section{Interrater Reliability}

During the first round of coding, the authors selected two or three institutions every month, independently coded the posts based on the initial adapted schema, met to discuss discrepancies, and identified the final code based on consensus. ${ }^{27}$ However, during these discussions, it became evident that there was substantial disagreement concerning how specific categories were interpreted. To examine the impact of this disagreement, the authors calculated Fleiss' kappa, which can be used to assess interrater reliability when two or more coders categorically evaluate data. ${ }^{28}$ Although this project's Fleiss' kappa (0.683554901) was relatively close to a score of 1.0, demonstrating moderate agreement between each of the three coders, the authors recognized that additional fine-tuning of the adapted coding schema would allow for a more accurate representation of the types of content shared by academic libraries. After updating the schema (table 1), a small sample of collected Instagram posts (20 percent, or 76 posts) was randomly selected for independent recoding by each of the authors. Again, after coding this random sample individually, the authors met to seek consensus. Anecdotal feedback from the coders, as well as an increase in the project's Fleiss' kappa (0.795494117), demonstrated that the updated coding schema was more robust and representative. Based on this evidence, the authors randomly distributed the remaining 301 posts amongst themselves; each post was coded by one author. 
Table 1. Coding Schema for Library Instagram Posts [Adapted from: Emma Stuart, David Stuart, and Mike Thelwall, "An Investigation of the Online Presence of UK Universities on Instagram," Online Information Review 41, no. 5 (2017): 588, https://doi.org/10.1108/0IR-02-2016-0057.]

\begin{tabular}{|c|c|c|c|c|}
\hline Category & Description & \multicolumn{3}{|l|}{ Example1 } \\
\hline Crowdsourcing & $\begin{array}{l}\text { Posts that were created } \\
\text { with the intention of } \\
\text { generating feedback } \\
\text { within the platform. If the } \\
\text { content of the post itself } \\
\text { fits within a different } \\
\text { classification category, } \\
\text { but the image is } \\
\text { accompanied by text that } \\
\text { explicitly asks for viewer } \\
\text { feedback, then the post } \\
\text { should be classified as } \\
\text { crowdsourcing. } \\
\text { Includes requests for } \\
\text { followers to like, } \\
\text { comment on, or tag } \\
\text { others in a particular } \\
\text { post. }\end{array}$ & & 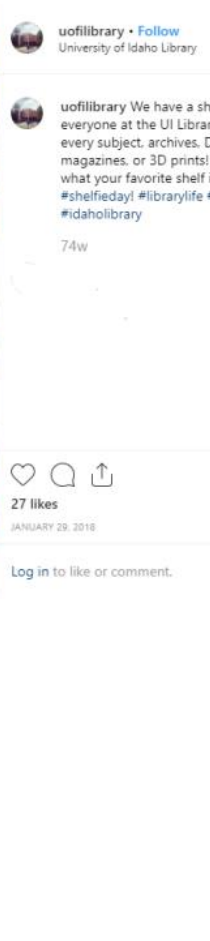 & $\ldots$ \\
\hline Humanizing & $\begin{array}{l}\text { Posts that aim to } \\
\text { emphasize human } \\
\text { character or elements of } \\
\text { warmth, humor, or } \\
\text { amusement. This includes } \\
\text { historic/archival photos } \\
\text { used to convey these } \\
\text { sentiments. } \\
\text { This code is only used if } \\
\text { both the text and the } \\
\text { photo or video can be } \\
\text { categorized as } \\
\text { humanizing because } \\
\text { many library posts } \\
\text { contain a "humanizing" } \\
\text { element. }\end{array}$ & & 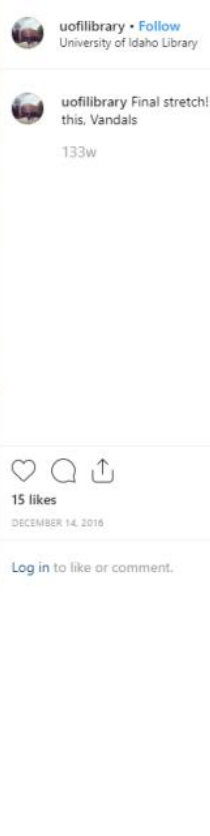 & \\
\hline
\end{tabular}




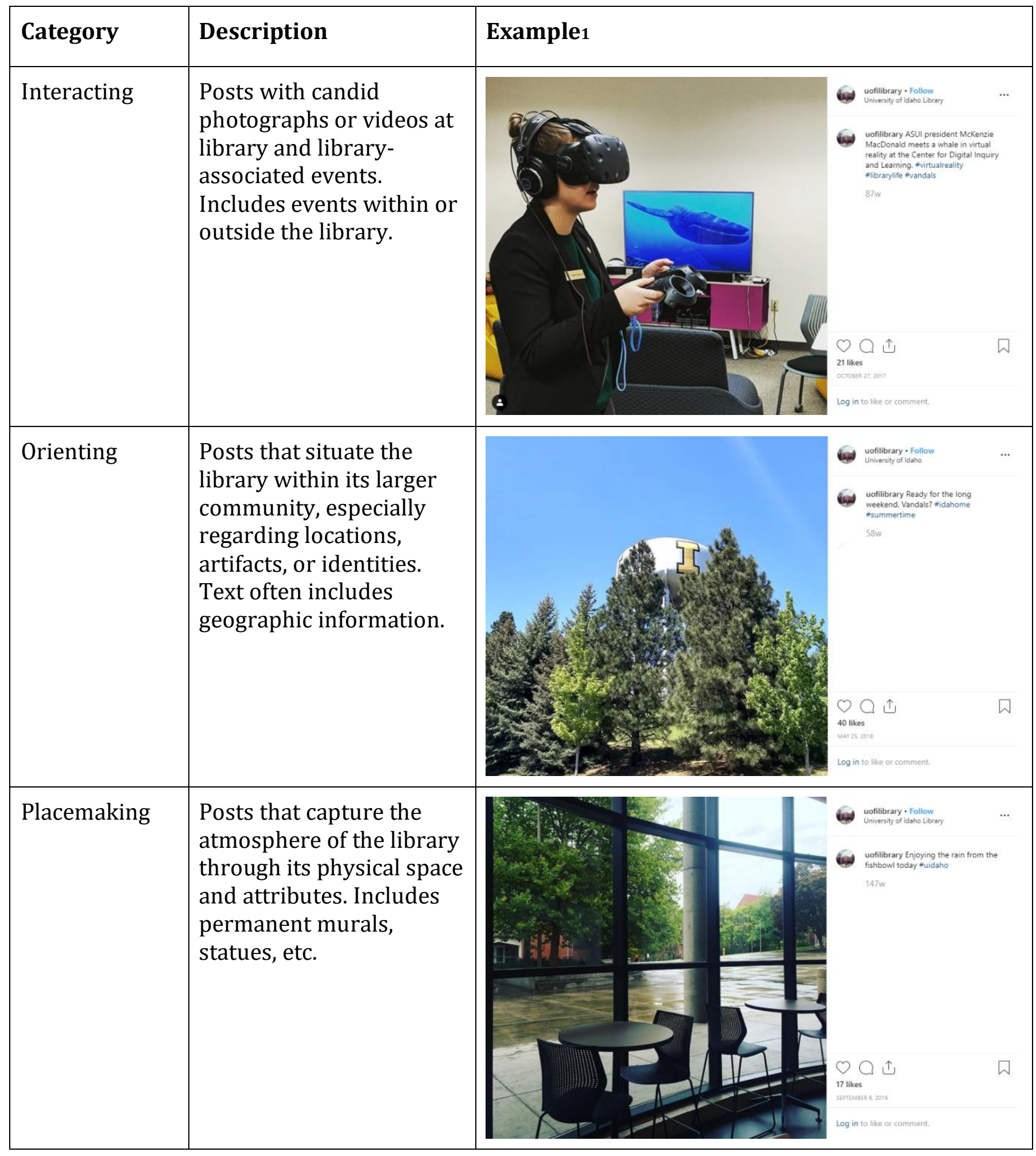




\begin{tabular}{|c|c|c|c|}
\hline Category & Description & Example1 & \\
\hline Showcasing & $\begin{array}{l}\text { Posts that highlight } \\
\text { library or campus } \\
\text { resources, services, or } \\
\text { future events. Can include } \\
\text { current or on-going } \\
\text { events if people are not } \\
\text { the focus of the image } \\
\text { (e.g. exhibit, highlight of } \\
\text { collection, etc.). These } \\
\text { posts can also present } \\
\text { information about library } \\
\text { operations, such as hours } \\
\text { and fundraising. Posts can } \\
\text { also entice their audience } \\
\text { to do something, outside } \\
\text { of Instagram, such as visit } \\
\text { a specific website. }\end{array}$ & $\begin{array}{l}\text { mell of the } \\
\text { mountains } \\
1901\end{array}$ & 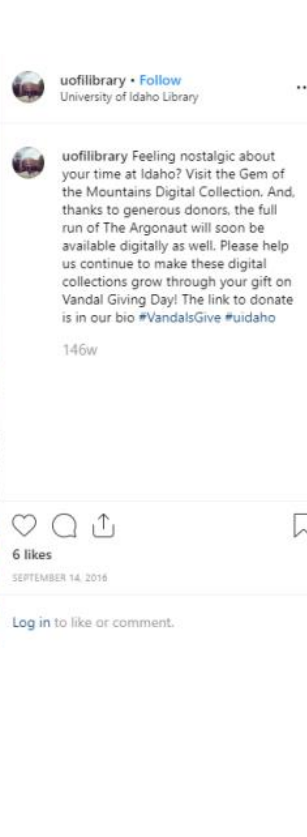 \\
\hline
\end{tabular}

\section{RESULTS}

\section{General Data about the Library Instagram Accounts}

As of October 23, 2018 (the date this initial information was gathered), the eleven academic library Instagram accounts had shared a combined 3,124 posts. Most libraries created their Instagram accounts and started posting between 2013 and 2016, but one library shared a post in 2012 and one created their account in April 2018. Since the date of their first post, each account had shared 284 posts on average, while the actual number of posts shared across accounts ranged from 62 to 520 . The number of followers and accounts followed across these eleven accounts ranged from 115 to 1,390 and 65 to 2,717, respectively. Between January 1, 2018, and June 30, 2018 , these eleven library Instagram accounts shared a total of 377 posts. The number of posts shared by each account during this time period ranged from four to 57, with an average of 34 posts.

\section{RQ1: Which Type of Post Category is Used most Frequently by Libraries on Instagram?}

Of the 377 posts analyzed, 359 included photos and 18 included videos. More than 50 percent of posts shared were coded as showcasing, with humanizing (18 percent) and crowdsourcing (9.8 percent) being the next most common categories (see table 2), although data demonstrated that individual libraries differed in their use of specific post categories (see table 3). When examining frequency based on category of post, the authors identified slight differences between video and photo posts. As with photos, the majority of videos (55.6 percent) were still coded as showcasing; however, the second most common post category for videos was interacting (16.7 percent). 
Table 2. Number and Percentage of Posts by Category for Posts with Photos or Videos

\begin{tabular}{|l|l|l|}
\hline Category & Number of Posts & Percentage of Posts \\
\hline Crowdsourcing & 38 & $10.1 \%$ \\
\hline Humanizing & 68 & $18.0 \%$ \\
\hline Interacting & 16 & $4.2 \%$ \\
\hline Orienting & 28 & $7.4 \%$ \\
\hline Placemaking & 33 & $8.8 \%$ \\
\hline Showcasing & 194 & $51.5 \%$ \\
\hline Total & $\mathbf{3 7 7}$ & $\mathbf{1 0 0} \%$ \\
\hline
\end{tabular}

Table 3. Percentage of Posts by Category and Library for Posts with Photos or Videos

\begin{tabular}{|l|l|l|l|l|l|l|}
\hline Library & Crowdsourcing & Humanizing & Interacting & Orienting & Placemaking & Showcasing \\
\hline Lib 1 & $7.7 \%$ & $15.4 \%$ & $0 \%$ & $23.1 \%$ & $30.8 \%$ & $23.1 \%$ \\
\hline Lib 2 & $4.2 \%$ & $50.0 \%$ & $0 \%$ & $4.2 \%$ & $0 \%$ & $41.7 \%$ \\
\hline Lib 3 & $56.1 \%$ & $10.5 \%$ & $1.8 \%$ & $3.5 \%$ & $7.0 \%$ & $21.1 \%$ \\
\hline Lib 4 & $0 \%$ & $4.1 \%$ & $4.1 \%$ & $4.1 \%$ & $2.0 \%$ & $85.7 \%$ \\
\hline Lib 5 & $0 \%$ & $24.4 \%$ & $2.2 \%$ & $20.0 \%$ & $26.7 \%$ & $26.7 \%$ \\
\hline Lib 6 & $7.5 \%$ & $18.9 \%$ & $3.8 \%$ & $11.3 \%$ & $11.3 \%$ & $47.2 \%$ \\
\hline Lib 7 & $0 \%$ & $20.0 \%$ & $0 \%$ & $0 \%$ & $10.0 \%$ & $70.0 \%$ \\
\hline Lib 8 & $0 \%$ & $21.6 \%$ & $9.8 \%$ & $5.9 \%$ & $0 \%$ & $62.7 \%$ \\
\hline Lib 9 & $0 \%$ & $25.0 \%$ & $25.0 \%$ & $0 \%$ & $0 \%$ & $50.0 \%$ \\
\hline Lib 10 & $0 \%$ & $16.1 \%$ & $6.5 \%$ & $0 \%$ & $9.7 \%$ & $67.7 \%$ \\
\hline Lib 11 & $0 \%$ & $15.0 \%$ & $5.0 \%$ & $5.0 \%$ & $5.0 \%$ & $70.0 \%$ \\
\hline
\end{tabular}

RQ2: Is the Number of Likes or the Existence of Comments Related to the Post Category?

Number of Likes by Category

The results of the coding process also indicated that the number of likes differed based on the category of post. When examining photo posts, the authors noted that every post received at least five likes, with most posts receiving between 20-39 likes (see table 4). On average, crowdsourcing 
photo posts generated the highest average number of likes across all categories, followed by orienting and placemaking posts (see table 5). However, it is important to recognize that crowdsourcing posts often asked visitors to participate in a post by "liking" it, often with the chance to win a library-sponsored contest, which may partially explain the higher average number of likes.

Table 4. Number of Posts by Category and Range of Likes for Posts with Photos (does not include posts with videos)

\begin{tabular}{|l|l|l|l|l|l|l|l|}
\hline & \multicolumn{7}{|c|}{ Range of Likes } \\
\hline Category & $5-19$ & $20-39$ & $40-59$ & $60-79$ & $80-99$ & $\begin{array}{l}100- \\
119\end{array}$ & $\begin{array}{l}120- \\
140\end{array}$ \\
\hline Crowdsourcing & 0 & 11 & 16 & 6 & 1 & 1 & 1 \\
\hline Humanizing & 16 & 26 & 10 & 9 & 5 & 0 & 1 \\
\hline Interacting & 5 & 5 & 3 & 0 & 0 & 0 & 0 \\
\hline Orienting & 2 & 7 & 9 & 8 & 0 & 1 & 0 \\
\hline Placemaking & 3 & 10 & 12 & 3 & 2 & 1 & 1 \\
\hline Showcasing & 67 & 83 & 27 & 5 & 1 & 0 & 1 \\
\hline Total & $\mathbf{9 3}$ & $\mathbf{1 4 2}$ & $\mathbf{7 7}$ & $\mathbf{3 1}$ & $\mathbf{9}$ & $\mathbf{3}$ & $\mathbf{4}$ \\
\hline
\end{tabular}

Table 5. Average Number of Likes by Category for Posts with Photos (does not include posts with videos)

\begin{tabular}{|l|l|l|}
\hline Category & Average Number of Likes & Number of Posts \\
\hline Crowdsourcing & 53.6 & 36 \\
\hline Humanizing & 39.9 & 67 \\
\hline Interacting & 27.8 & 13 \\
\hline Orienting & 50.0 & 27 \\
\hline Placemaking & 46.9 & 32 \\
\hline Showcasing & 27.6 & 184 \\
\hline
\end{tabular}

Existence of Comments by Category

The authors also examined the existence of comments, another metric for engagement with Instagram posts. Data demonstrated that 78.9 percent of crowdsourcing posts included 
comments, while a much lower percentage of placemaking (30.3 percent), orienting (28.6 percent), and humanizing (26.5 percent) posts generated this type of engagement (see table 6). As with the data on the number of "likes," many crowdsourcing posts encouraged visitors to comment on a particular post, at times with an incentive connected to this type of engagement.

Table 6. Presence of Comments by Category for Posts with Photos or Videos

\begin{tabular}{|l|l|l|l|l|}
\hline Category & $\begin{array}{c}\text { Number of } \\
\text { Posts with } \\
\text { Comments }\end{array}$ & $\begin{array}{c}\text { Number of } \\
\text { Posts without } \\
\text { Comments }\end{array}$ & $\begin{array}{c}\text { Total Number } \\
\text { of Posts }\end{array}$ & $\begin{array}{c}\text { Percentage of } \\
\text { Posts with } \\
\text { Comments }\end{array}$ \\
\hline Crowdsourcing & 30 & 8 & 38 & $78.9 \%$ \\
\hline Humanizing & 18 & 50 & 68 & $26.5 \%$ \\
\hline Interacting & 3 & 13 & 16 & $18.8 \%$ \\
\hline Orienting & 8 & 20 & 28 & $28.6 \%$ \\
\hline Placemaking & 10 & 23 & 33 & $30.3 \%$ \\
\hline Showcasing & 40 & 154 & 194 & $20.6 \%$ \\
\hline Total & $\mathbf{1 0 9}$ & $\mathbf{2 6 8}$ & $\mathbf{3 7 7}$ & $\mathbf{2 8 . 9 \%}$ \\
\hline
\end{tabular}

\section{DISCUSSION}

As noted previously, the post category used most frequently by these eleven libraries on Instagram was showcasing (51.5 percent). The fact that libraries were more likely to share this type of content-which highlighted library resources, events, or collections-is understandable, as library promotion is one of the foundational reasons libraries spend the time and effort required to maintain social media accounts.$^{29}$ This finding differs substantially from previous research with UK universities, which classified only 28.8 percent of posts as showcasing. ${ }^{30}$ When examining other post categories, it also became clear that UK universities shared humanizing posts more frequently (31 percent) than the eleven libraries (18 percent) included in this study. ${ }^{31}$ Although the results of this study demonstrated that showcasing posts were shared most often, the data also indicates that showcasing posts were neither the category with the most likes on average nor the category that received comments most often. Crowdsourcing posts were the category with the highest average number of likes (53.6) with orienting posts coming in at a close second (50), followed by placemaking (46.9) and humanizing (39.9) posts. Showcasing posts, along with interacting posts, only generated slightly more than half the number of likes on average, when compared to the other categories (27.6 and 27.8, respectively). The category with the largest proportion of comments was crowdsourcing posts, with 78.9 percent of posts in this category generating comments from visitors. However, this result is likely skewed, as one of the library Instagram accounts had exceptionally successful crowdsourcing posts, which often included a giveaway or other incentive for participation. In fact, when this institution was removed from the data set, only six crowdsourcing posts remained, two of which generated 
comments. To better determine whether crowdsourcing posts are always this effective at generating engagement, it would be necessary to code a larger sample of Instagram posts.

It is clear that while showcasing posts were the most common among the Instagram accounts analyzed, they also received the lowest number of likes, on average, and generated comments less frequently than all but one post category. While this may seem disheartening, it is important to remember that the showcasing category includes informational posts that convey library hours, services, or closures; this information that may be effectively relayed to users without necessitating an active response in the form of likes and comments. Therefore, one might use different criteria to determine the success of showcasing posts, perhaps examining Instagram data related to reach (the total number of unique visitors that view a post) and impressions (the total number of times a post is viewed). ${ }^{32}$ Data on reach and impressions are only available to Instagram account "owners." In the current study, the authors did not quantify these types of engagement as their goal was to evaluate the content and metrics available to all Instagram users, rather than the data that was only available to the "owners" of these library Instagram accounts.

In addition to answering the research questions, coding these Instagram posts prompted several new questions regarding the types of information libraries and other institutions share online. One such question includes: With both universities and academic libraries working with students, why did academic libraries share a smaller percentage of interacting posts than UK universities? ${ }^{33}$ Additional research is needed to answer this question, but anecdotally, this difference may be related to the fact that universities, as a whole, have a larger number of opportunities to promote and share instances of interaction via Instagram than libraries. For example, general university Instagram accounts often include photos of students and affiliates interacting at large scale events such as sports games, musical performances, and other student gatherings that take place across campus. Library-specific accounts on the other hand, have fewer opportunities to post photos that capture individuals "interacting" candidly. Further, the fact that libraries tend to be proponents of privacy rights may inhibit library staff from taking photos of their users and sharing them online without first getting permission. Therefore, differences related to the number of events and the organization type may contribute to whether or not universities and libraries share interacting posts; more research is needed to examine this hypothesis.

Another issue that arose during coding was that, if not for their inclusion of a request to comment, many crowdsourcing posts could have been classified under other categories. If an account follower looked only at the photos included in many of the crowdsourcing posts without reading the captions, they may not interpret those posts as crowdsourcing. Therefore, a future research project might examine whether applying secondary categories to crowdsourcing posts, as a means of further classifying images and not just their captions, could generate a more comprehensive picture of what libraries are sharing on their Instagram accounts.

The authors also discovered that a majority of the library Instagram posts included in this sample contained humanizing elements. Almost all posts attempted to convey warmth, humor, or assistance, and therefore had the potential to be classified as humanizing. To successfully adapt Stuart et al.'s coding schema for academic library Instagram accounts, the authors specified that a post had to have both a humanizing caption as well as a humanizing photo to be coded as such. ${ }^{34}$ As with crowdsourcing posts, adding secondary categories to humanizing posts could better reflect the dual nature of this content and help future coders more accurately interpret the types of content shared by academic libraries. 


\section{LIMITATIONS AND FUTURE RESEARCH}

The number of library Instagram accounts selected as well as the use of a six-month timeframe were limitations of the current study. In the future, selecting a larger sample size and a different group of academic libraries would serve to advance the discipline's understanding of the types of content shared by academic libraries and how users interact with these Instagram posts. Additionally, collecting Instagram posts shared during an expanded timeframe could allow researchers to explore whether library Instagram accounts consistently share the same types of content at various points throughout the year. As mentioned in the Discussion section, future research could also include adding secondary categories to posts, which would allow researchers to gather more granular information about the types of content shared and the relationships between post category, comments, and likes.

Lastly, to better understand the post categories that generate the greatest engagement, collaborative research between institutions could allow researchers to gather and analyze metrics that are only available to account owners, such as impressions and reach. With this type of collaboration, researchers could also investigate how social media outreach goals influence the types of content shared on library Instagram accounts. For example, researchers could conduct interviews or surveys with libraries and ask questions such as: what does your library hope to accomplish with its Instagram account, who are you attempting to reach, how do you define a successful post, what metrics do you use to evaluate your Instagram presence, and do your social media outreach goals influence the types of content shared on Instagram? Pursuing these types of questions, in addition to examining the actual content shared, would allow researchers to gain a more complete picture of what a successful social media presence looks like for an academic library.

\section{CONCLUSION}

This research provides initial insight into the Instagram presence of a subset of academic libraries at land-grant institutions in the United States. Expanding on the research of Stuart et al., this project used an adapted coding schema to document and analyze the content and efficacy of academic libraries' Instagram posts. ${ }^{35}$ The results of this study suggest that social media accounts, including those used by academic libraries, perform better when they reflect the community the library inhabits by highlighting content that is unique to their particular constituents, rather than simply functioning as another platform through which to share information. This study's findings also demonstrate that academic libraries should strive to create an Instagram presence that encompasses a variety of post categories to ensure that their online information sharing meets various needs. 


\section{ENDNOTES}

${ }^{1}$ Nancy Dowd, “Social Media: Libraries are Posting, but is Anyone Listening?," Library Journal 138, no. 10 (May 7, 2013), 12, https://www.libraryjournal.com/?detailStory=social-media-libraries-areposting-but-is-anyone-listening.

${ }^{2}$ Marshall Breeding, Next-Gen Library Catalogs (London: Facet Publishing, 2010); Zelda Chatten and Sarah Roughley, "Developing Social Media to Engage and Connect at the University of Liverpool Library," New Review of Academic Librarianship 22, no. 2/3 (2016), https://doi.org/10.1080/13614533.2016.1152985; Amanda Harrison et al., "Social Media Use in Academic Libraries: A Phenomenological Study," The Journal of Academic Librarianship 43, no. 3 (2017), https://doi.org/10.1016/j.acalib.2017.02.014; Nicole Tekulve and Katy Kelly, "Worth 1,000 Words: Using Instagram to Engage Library Users," Brick and Click Libraries Symposium, Maryville, MO (2013), https://ecommons.udayton.edu/roesch_fac/20; Evgenia Vassilakaki and Emmanouel Garoufallou, "The Impact of Twitter on Libraries: A Critical Review of the Literature," The Electronic Library 33, no. 4 (2015), https://doi.org/10.1108/EL03-2014-0051.

${ }^{3}$ Yeni Budi Rachman, Hana Mutiarani, and Dinda Ayunindia Putri, "Content Analysis of Indonesian Academic Libraries' Use of Instagram," Webology 15, no. 2 (2018), http://www.webology.org/2018/v15n2/a170.pdf; Catherine Fonseca, "The Insta-Story: A New Frontier for Marking and Engagement at the Sonoma State University Library," Reference \& User Services Quarterly 58, no. 4 (2019), https://www.journals.ala.org/index.php/rusq/article/view/7148; Kjersten L. Hild, "Outreach and Engagement through Instagram: Experiences with the Herman B Wells Library Account," Indiana Libraries 33, no. 2 (2014), https://journals.iupui.edu/index.php/IndianaLibraries/article/view/16633; Julie Lê, "\#Fashionlibrarianship: A Case Study on the Use of Instagram in a Specialized Museum Library Collection," Art Documentation: Bulletin of the Art Libraries Society of North America 38, no. 2 (2019), https://doi.org/10.1086/705737; Danielle Salomon, "Moving on from Facebook: Using Instagram to Connect with Undergraduates and Engage in Teaching and Learning," College \& Research Libraries News 74, no. 8 (2013), https://doi.org/10.5860/crln.74.8.8991.

4 "Our Story," Instagram, https://business.instagram.com/; Chloe West, "17 Instagram Stats Marketers Need to Know for 2019," Sprout Blog, April 22, 2019, https://web.archive.org/web/20191219192653/https://sproutsocial.com/insights/instagra m-stats/; Pew Research Center, "Social Media Fact Sheet," last modified June 12, 2019, http://www.pewinternet.org/fact-sheet/social-media/.

5 "Our Story," Instagram.

${ }^{6}$ Joe Phua, Seunga Venus Jin, and Jihoon Jay Kim, “Gratifications of Using Facebook, Twitter, Instagram, or Snapchat to Follow Brands: The Moderating Effect of Social Comparison, Trust, Tie Strength, and Network Homophily on Brand Identification, Brand Engagement, Brand Commitment, and Membership Intention," Telematics and Informatics 34, no. 1 (2017), https://doi.org/10.1016/j.tele.2016.06.004. 
${ }^{7}$ Fonseca, "The Insta-Story;” Hild, "Outreach and Engagement;" Lê, “\#Fashionlibrarianship;” Rachman, Mutiarani, and Putri, "Content Analysis;" Salomon, "Moving on from Facebook;" Tekulve and Kelly, "Worth 1,000 Words."

${ }^{8}$ Vassilakaki and Garoufallou, "The Impact of Twitter."

${ }^{9}$ Breeding, Next-Gen Library Catalogs; Hild, "Outreach and Engagement;" Rachman, Mutiarani, and Putri, "Content Analysis;" Vassilakaki and Garoufallou, "The Impact of Twitter."

${ }^{10}$ Harrison, Burress, Velasquez, Schreiner, “Social Media Use," 253.

${ }^{11}$ Chatten and Roughley, "Developing Social Media."

${ }^{12}$ Peter Fernandez, “'Through the Looking Glass: Envisioning New Library Technologies' Social Media Trends that Inform Emerging Technologies," Library Hi Tech News 33, no. 2 (2016), https://doi.org/10.1108/LHTN-01-2016-0004.

${ }^{13}$ Robin M. Hastings, Microblogging and Lifestreaming in Libraries (New York: Neal-Schumann Publishers, 2010).

${ }^{14}$ Hastings, Microblogging.

${ }^{15}$ Robert David Jenkins, “How Are U.S. Startups Using Instagram? An Application of Taylor's SixSegment Message Strategy Wheel and Analysis of Image Features, Functions, and Appeals" (MA thesis, Brigham Young University, 2018), https://scholarsarchive.byu.edu/etd/6721.

${ }^{16}$ Lucy Hitz, "Instagram Impressions, Reach, and Other Metrics you Might be Confused About," Sprout Blog, January 22, 2020, https://sproutsocial.com/insights/instagram-impressions/.

${ }^{17}$ Vassilakaki and Garoufallou, "The Impact of Twitter."

${ }^{18}$ Mark Aaron Polger and Karen Okamoto, "Who's Spinning the Library? Responsibilities of Academic Librarians who Promote," Library Management 34, no. 3 (2013), https://doi.org/10.1108/01435121311310914.

${ }^{19}$ Yuhen Hu, Lydia Manikonda, and Subbarao Kambhampati, "What We Instagram: A First Analysis of Instagram Photo Content and User Types," Eighth International AAAI Conference on Weblogs and Social Media (2014), https://www.aaai.org/ocs/index.php/ICWSM/ICWSM14/paper/viewPaper/8118; Jenkins, "How Are U.S. Startups Using Instagram?;" Brian J. McNely, "Shaping Organizational ImagePower Through Images: Case Histories of Instagram," Proceedings of the 2012 IEEE International Professional Communication Conference, Piscataway, NJ (2012), https://doi.org/10.1109/IPCC.2012.6408624; Emma Stuart, David Stuart, and Mike Thelwall, "An Investigation of the Online Presence of UK Universities on Instagram," Online Information Review 41, no. 5 (2017): 584, https://doi.org/10.1108/0IR-02-2016-0057.

${ }^{20}$ Stuart, Stuart, and Thelwall, "An Investigation of the Online Presence;" McNely, "Shaping Organizational Image-Power," 3. 
${ }^{21}$ Stuart, Stuart, and Thelwall, “An Investigation of the Online Presence.”

${ }^{22}$ Stuart, Stuart, and Thelwall, “An Investigation of the Online Presence,” 588.

${ }^{23}$ Stuart, Stuart, and Thelwall, “An Investigation of the Online Presence,” 585.

24 “University of Idaho's peer institutions," University of Idaho, accessed October 8, 2019.

${ }^{25}$ Stuart, Stuart, and Thelwall, “An Investigation of the Online Presence,” 588.

${ }^{26}$ McNely, "Shaping Organizational Image-Power," 4; Stuart, Stuart, and Thelwall, "An Investigation of the Online Presence," 588.

${ }^{27}$ Johnny Saldaña, The Coding Manual for Qualitative Researchers (Los Angeles: Sage Publications, 2013), 27.

28 “Fleiss' Kappa," Wikipedia, https://en.wikipedia.org/wiki/Fleiss\%27_kappa.

${ }^{29}$ Chatten and Roughley, "Developing Social Media."

${ }^{30}$ Stuart, Stuart, and Thelwall, “An Investigation of the Online Presence,” 590.

${ }^{31}$ Stuart, Stuart, and Thelwall, “An Investigation of the Online Presence,” 590.

${ }^{32}$ Hitz, "Instagram Impressions, Reach, and Other Metrics."

${ }^{33}$ Stuart, Stuart, and Thelwall, “An Investigation of the Online Presence," 590.

${ }^{34}$ Stuart, Stuart, and Thelwall, “An Investigation of the Online Presence," 588.

${ }^{35}$ Stuart, Stuart, and Thelwall, “An Investigation of the Online Presence.” 